\title{
Targeted Delivery of Contrast Agents to the Tympanic Medial Wall at Minimum Amount and the Efficient Uptake in the Inner Ear through Oval and Round Windows
}

\author{
Zou J ${ }^{1,2 *}$, Ostrovsky $\mathrm{S}^{3}$, Israel LL ${ }^{3}$, Lellouche J P ${ }^{3}$ \\ and Pyykkö I ${ }^{1}$ \\ ${ }^{1}$ Hearing and Balance Research Unit, Field of Oto- \\ laryngology, School of Medicine, University of Tampere, \\ Finland \\ ${ }^{2}$ Department of Otolaryngology-Head and Neck Surgery, \\ Changhai Hospital, Second Military Medical University, \\ China \\ ${ }^{3}$ Institute of Nanotechnology \& Department of Chemistry, \\ Bar-Ilan University, Israel \\ *Corresponding author: Zou J , Hearing and Balance \\ Research Unit, Field of Oto-laryngology, School of \\ Medicine, University of Tampere, Medisiinarinkatu 3, \\ 33520 Tampere, Finland
}

Received: August 05, 2015; Accepted: September 02, 2015; Published: September 03, 2015

\section{Introduction}

Gadolinium-enhanced inner ear MRI became a valuable diagnostic tool in inner ear diseases after two milestone studies showed that the cochlear scalae were distinguishable, and that the experimental endolymphatichy drops was visible in vivo in $4.7 \mathrm{~T}$ MRI after intravenous injection of Gadolinium Diethylenetriaminepentaacetic Acid Bismethylamide (Gd-DTPA-BMA) in guinea pigs [1-3]. In the studies, high-dose Gadolinium chelate (GdC) was applied intravenously to induce enough distribution in the inner ear because GdC has poor transport efficacy across the blood-perilymph barrier [4-6]. However, high doses of GdC can cause renal injury and even nephrogenic systemic fibrosis.

High contrast images of all cochlear turns were obtained after placing GdC on the round window membrane. Auditory brainstem response measurements showed no significant threshold shifts after the application, indicating that gadolinium is non-toxic to the guinea pig cochlea [7]. In 2005, the perilymphatic and endolymphatic spaces were first demonstrated separately in humans using a $1.5 \mathrm{~T}$ machine after transtrympanic injection of GdC [8]. In 2007, clear visualization of endolymphatic hydrops in patients with Meniere's disease was demonstrated on a $3.0 \mathrm{~T}$ machine with Three-Dimensional Fluid-Attenuated Inversion Recovery (3D-FLAIR) sequence after transtymanic injection of GdC diluted eightfold with saline [9]. In order to further reduce the amount of contrast agent applied to the body, a targeted delivery of GdC to the medial wall of the middle ear cavity was developed in a minimally invasive way and generated efficient uptake of GdC in the inner ear in 2011 [10]

Novel contrast agents, such as manganese and Super Paramagnetic
Iron Oxide Nanoparticles (SPIONs), were also tested in targeted delivery system and demonstrated efficient uptake in the inner ear (see following text). Pautler et al. first reported that Manganese-Enhanced MRI (MEMRI) was capable of tracking neuronal connections in vivo in the nose and eyes of mice after topical administration [11]. The mechanism underlying the analysis is that the $\mathrm{Mn}^{++}$acts as a $\mathrm{Ca}^{++}$ agonist in addition to its T1 contrast effect. MEMRI was used to trace the central auditory pathway in the living animals after either topical or systemic administration because $\mathrm{Mn}^{++}$ions enter excitable cells through voltage-gated calcium channels [12-14]. Recently, alterations in calcium handling (possibly due to $\mathrm{Ca}^{++}$-ATPase dysfunction) in preclinical models of cardiac hypertrophy were visualized using MEMRI [15]. That report broadened the application of MEMRI from detecting neuronal activities to monitoring $\mathrm{Ca}^{++}$homeostatic maintenance. It is important to trace the $\mathrm{Ca}^{++}$transport in the inner ear in vivo using MEMRI.

SPIONs have been proven to be highly efficient MRI contrast agents, and several SPION formulations such asFerridex I.V. for liver and spleen imaging and Combidex ${ }^{\oplus}$ for imaging lymph node metastases have been approved for clinical use. In inner ear imaging, SPIONs hierarchically coated with oleic acid and Pluronic F127 copolymers demonstrated a high contrast effect and were capable of singling out the bright endolymph from the dark perilymph distributed with SPIONs using MRI [16]. SPIONs have attracted considerable attention for the early detection of diseases including inflammatory and tumor markers due to their specific physicochemical properties and molecular imaging capabilities [1719]. Recently, pre-formed Massart magnetite $\left(\mathrm{Fe}_{3} \mathrm{O}_{4}\right)$ Nanoparticles (NPs) have been modified by positively charged lanthanide Ce (III/
Austin J Radiol - Volume 2 Issue 6 - 2015

ISSN : 2473-0637 | www.austinpublishing group.com

Zou et al. $($ All rights are reserved
Citation: Zou J, Ostrovsky S, Israel LL, Lellouche JP and Pyykkö I. Targeted Delivery of Contrast Agents to the Tympanic Medial Wall at Minimum Amount and the Efficient Uptake in the Inner Ear through Oval and Round Windows. Austin J Radiol. 2015; 2(6): 1034 


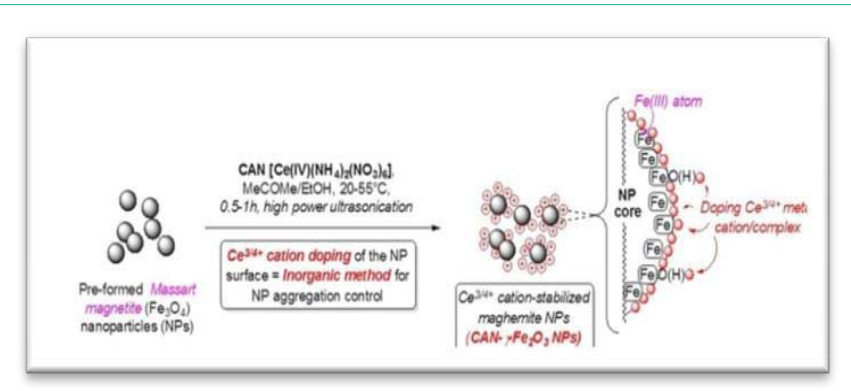

Figure 1: Overall fabrication of super-paramagnetic CAN- $-\mathrm{Fe} \mathrm{O}_{2} \mathrm{O}_{3} \mathrm{NPS}$ showing NP surface doping $\mathrm{Ce}^{3 / 4+}$ cations.

IV) cations $/\left[\mathrm{CeL}_{\mathrm{n}}\right]^{3 / 4+}$ complexes by using a strong mono-electronic Ceric Ammonium Nitrate oxidant (CAN) as Ce donor. The doping process is promoted by high-power ultrasonic irradiation [20]. The reaction has been statistically optimized by Design of Experiments (DoE, MINITAB 16 DoE software) to afford globally optimized, magnetically responsive ultra-small $6.61 \pm 2.04 \mathrm{~nm}$-sized $\mathrm{CAN}_{\mathrm{DOE}}-\gamma$ $\mathrm{Fe}_{2} \mathrm{O}_{3}$ NPs that are highly positively charged ( $\xi$ potential: $+45.7 \mathrm{mV}$ ) (Figure 1). This innovative inorganic DoE-optimized NP platform technology paves an efficient way for the successful development of a wide range of biomedicine and diagnostic-related applications.

\section{Structures of the tympanic cavity and the oval and round windows}

The tympanic cavity is a small cavity surrounding the bones of the middle ear that comprises the lateral wall (tympanic membrane), the medial wall (oval window, round window, promontory, and the prominence of the facial canal), the roof (the tegmen tympani), the floor (the jugular wall), the anterior wall (carotid wall) (Eustachian tube), and the posterior wall (or mastoid wall) (Figure 2). The ossicular chain connects the tympanic membrane on the lateral wall to the oval window on the medial wall to couple the air vibration with fluid vibration. Traditionally, the round window was considered to be

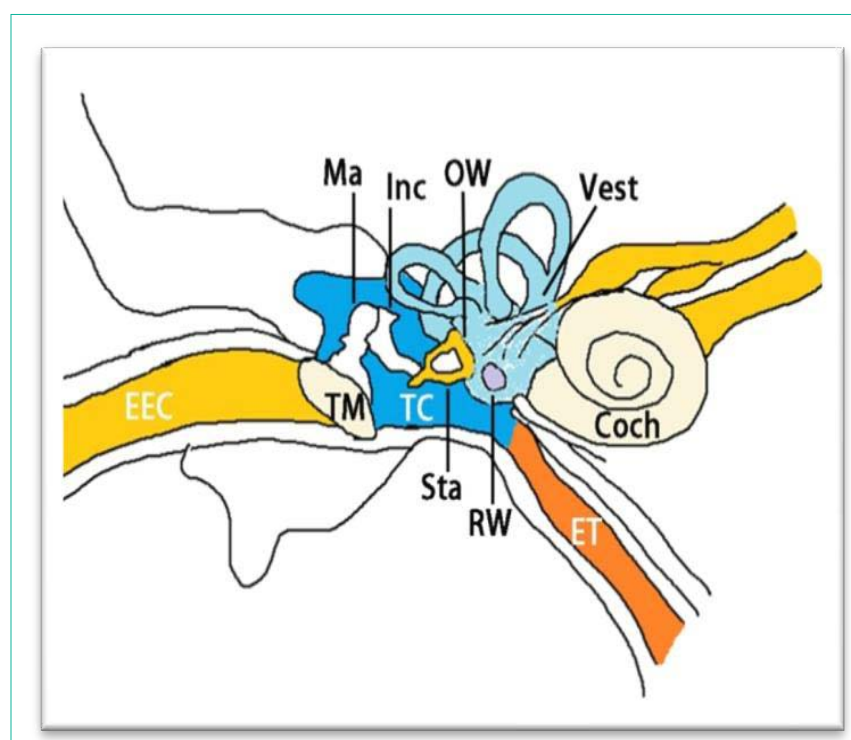

Figure 2: Illustration of the tympanic cavity. Coch: Cochlea; EEC: Externa Ear Canal; ET: Eustachian Tube; Inc: Incus; Ma: Malleus; OW: Oval Window; RW: Round Window; Sta: Stapes; TC: Tympanic Cavity: TM: Tympanic Membrane; Vest: Vestibule. the principal communication site between the middle and inner ears. Therefore, agents were administered to the round window membrane to induce efficient uptake in the inner ear for both animal experiments and clinical applications. However, this view was challenged by a study in rats that showed that the oval window passage is significantly more efficient for $\mathrm{GdC}$ than the round window membrane $[21,22]$.

There is histological basis for the different passage of GdC through the oval and round windows. The round window membrane is a sandwich-like structure that is composed of an outer squamous epithelial layer that faces the middle ear cavity, a medial connective tissue core, and an inner mesothelial layer that faces the scala tympani. The outer layer is composed of one or two layers of low cuboidal cells continuous with the epithelium of the middle ear. Tight junctions are present near the cell surfaces. The middle layer contains numerous fibrocytes, occasional fibroblasts, collagen fibers, elastic fibers, vessels, and both myelinated and unmyelinated nerves. The inner layer consists of mesothelial cells continuous with the lining of the scala tympani. The cellular extensions are connected by gap junctions $[23,24]$. A histologic study in rats demonstrated that the annular ligament across the stapediovestibular joint is a porous structure composed of fibdllin, $36 \mathrm{kD}$ microfibdl-associated glycoprotein, and hyaluronic acid [25]. Permeability of the oval window was proven in guinea pigs using Horseradish Peroxidase (HRP) as tracer [26].

\section{Technique for targeted delivery to the tympanic medial} wall

For the small animal study, the injection device was prepared as follows [10]. A High-Performance Polyimide Microlumen (HPPM) was cut (inner diameter $122 \mu \mathrm{m}$, outer diameter $180 \mu \mathrm{m}$, Micro Lumen Inc., Florida, USA) into $30-\mathrm{mm}$ pieces with a beveled tip at one end, which was then connected to polyethylene tubing (inner diameter $280 \mu \mathrm{m}$, outer diameter $610 \mu \mathrm{m}$, PEIO, Beeton, Dickinson and Company, New Jersey, USA), and sealed with Loctite Super Attak Plastic glue (Henkel, Germany). The other end of the catheter was connected to an insulin syringe (Becton, Dickinson and Company, USA) through a 27 -gauge needle. The tubing was then primed with GdC (500 mM). Under a microscope, the tympanic membrane was penetrated at the upper edge of the posterior upper quadrant with a 25-gauge needle, and the HPPM was inserted through the hole until it touched the medial wall of the middle ear cavity. A total volume of $2.5 \mu \mathrm{L}$ of $\mathrm{GdC}$ or $\mathrm{MnCl}_{2}(500 \mathrm{mM})$ was injected onto the medial wall of the middle ear cavity. The animals remained in the lateral position with the injected ear upward for $15 \mathrm{~min}$.

\section{Synthesis and characterization of $\mathrm{CAN}_{\mathrm{DOE}}-\mathrm{Y}-\mathrm{Fe}_{2} \mathrm{O}_{3} \mathrm{NPS}$}

Experimental procedure for nanocarrier fabrication - Starting neat neutral magnetite $\left(\mathrm{Fe}_{3} \mathrm{O}_{4}\right)$ nanoparticles $\left(\mathrm{Fe}_{3} \mathrm{O}_{4} \mathrm{NPs}\right.$, basic Massart hydrolytic method)

A solution of $\mathrm{FeCl}_{3} \cdot 6 \mathrm{H}_{2} \mathrm{O}(240.0 \mathrm{mg}, 0.9 \mathrm{mmol})$ dissolved in deoxygenated milliQ purified $\mathrm{H}_{2} \mathrm{O}(4.5 \mathrm{~mL})$ was mixed with an aqueous solution of $\mathrm{FeCl}_{2} \bullet 4 \mathrm{H}_{2} \mathrm{O}\left(97.5 \mathrm{mg}, 0.45 \mathrm{mmol}, 4.5 \mathrm{~mL} \mathrm{H}_{2} \mathrm{O}\right)$. This solution was kept under $\mathrm{N}_{2}$ and ultrasonicated (Bransonic ${ }^{\circ}$ ultrasonic cleaner bath, 2510E MTH model, $42 \mathrm{KHz}$ at full power) for 5-10 $\mathrm{min}$ at room temperature. Then, a concentrated $24 \%$ weight aqueous $\mathrm{NH}_{4} \mathrm{OH}(0.75 \mathrm{~mL})$ was introduced in one shot, resulting in an immediate black precipitation of magnetite $\left(\mathrm{Fe}_{3} \mathrm{O}_{4}\right)$ NPs. Sonication was continued for 10 additional minutes. The resulting $\mathrm{Fe}_{3} \mathrm{O}_{4} \mathrm{NPs}$ 


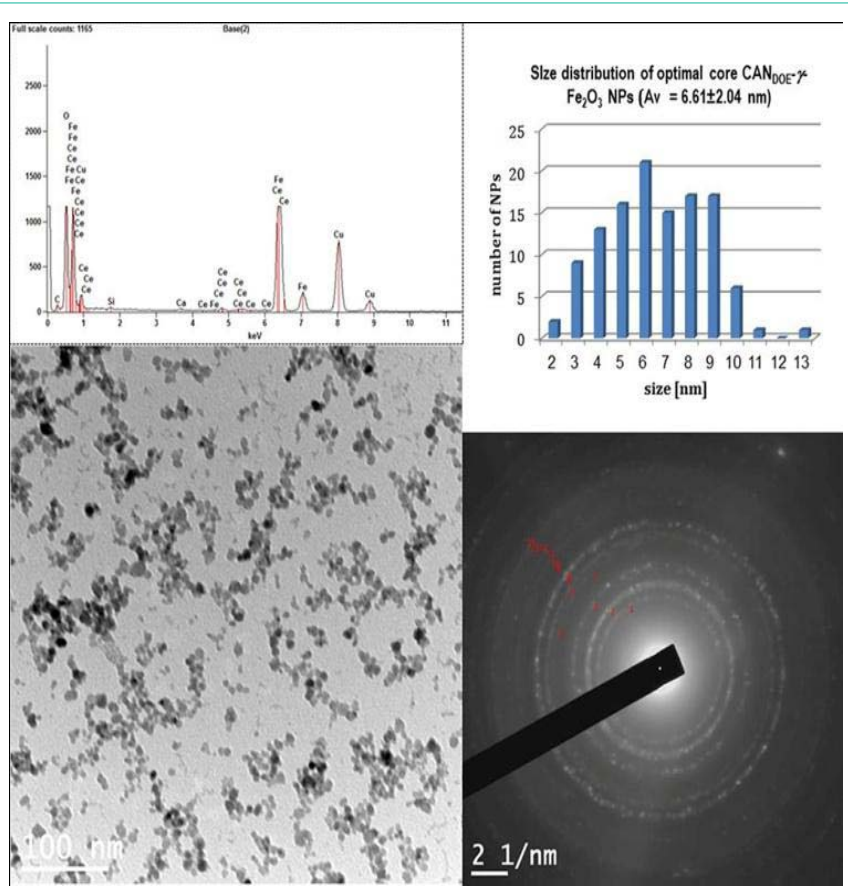

Figure 3: Transmission electron microscopy (bottom-left, scale bar: $100 \mathrm{~nm}$ ) microphotograph of ultra-small $6.61 \pm 2.04 \mathrm{~nm}$-sized core CANDOE- $\gamma-F e 2 \mathrm{O} 3$ NPs with TEM/Selected Area Electron Diffraction (SAED) patterns (bottomright): \#1 (plane 220), \#2 (plane 311), \#3 (plane 400), \& \#6 (plane 440), compositional EDAX analysis (top left) showing the presence of both $\mathrm{Fe} \& \mathrm{Ce}$ elements \& size distribution histogram of ultra-small 6.61 $\pm 2.04 \mathrm{~nm}$-sized core CANDOE- $\gamma-F e 2 O 3$ NPs (MINITAB® 16 software profile optimizer tool output, TEM microphotograph analysis, top right).

were transferred into a glass bottle $(100 \mathrm{~mL})$, magnetically decanted (using a strong external magnet), and washed with $\mathrm{ddH}_{2} \mathrm{O}(3 \times 40$ $\mathrm{mL}$ ) until neutrality. Then, brilliant black free flowing magnetite NPs were stored as a $30 \mathrm{~mL} \mathrm{NP}$ suspension in $\mathrm{ddH}_{2} \mathrm{O}$ before any further processing. Finally, an ageing process must be executed for at least a minimum storage time in these conditions of $2 \mathrm{~h}$ (room temperature).

Experimental procedure for DoE-optimized nanocarrier fabrication (MINITAB ${ }^{\circ} 16$ DoE software, version 16.2.4, Minitab Inc., profile optimizer tool) - $\mathrm{CAN}_{\mathrm{DOE}^{-}}$-stabilized maghemite nanoparticles $\left(\mathrm{CAN}_{\mathrm{DOE}}-\gamma-\mathrm{Fe}_{2} \mathrm{O}_{3} \mathrm{NPs}\right)$

First, the former aqueous magnetite NP suspension $(30 \mathrm{~mL}, 4.22$ $\mathrm{h}$ ageing time) was magnetically decanted to separate the magnetite NPs from its aqueous storage phase. Ceric ammonium Nitrate $\left(\mathrm{CAN},\left(\mathrm{NH}_{4}\right)_{2} \mathrm{Ce}(\mathrm{IV})\left(\mathrm{NO}_{3}\right)_{6}, 500.0 \mathrm{mg}, 0.912 \mathrm{mmol}\right)$ dissolved in $6.0 \mathrm{~mL}$ MeCOMe was introduced onto the decanted magnetite NPs, followed by the addition of degassed milliQ purified $\mathrm{H}_{2} \mathrm{O}(18.0 \mathrm{~mL})$. The corresponding mixture was ultrasonicated using a high-power sonicator (Sonics ${ }^{\oplus}$, Vibra cell, 750 Watt, power modulator set-up at $25 \%)$ equipped with a titanium horn $\left(0.5 \mathrm{~h}, 0^{\circ} \mathrm{C}\right)$ under an inert argon atmosphere.

At this stage and optionally, the resulting highly stabilized hydrophilic $\mathrm{CAN}_{\mathrm{DOE}}-\gamma-\mathrm{Fe}_{2} \mathrm{O}_{3}$ NPs might be purified for other purposes [washing with $\mathrm{ddH}_{2} \mathrm{O}(3 \times 10 \mathrm{~mL})$ using an Amicon Ultra-15 centrifugal filter device $(100 \mathrm{~K})$ processed at 4,000 rpm during 5-6 $\mathrm{min}\left(\mathrm{rt}, 18^{\circ} \mathrm{C}\right)$ and re-dispersed in $\left.\mathrm{ddH}_{2} \mathrm{O}(15 \mathrm{~mL})\right]$.

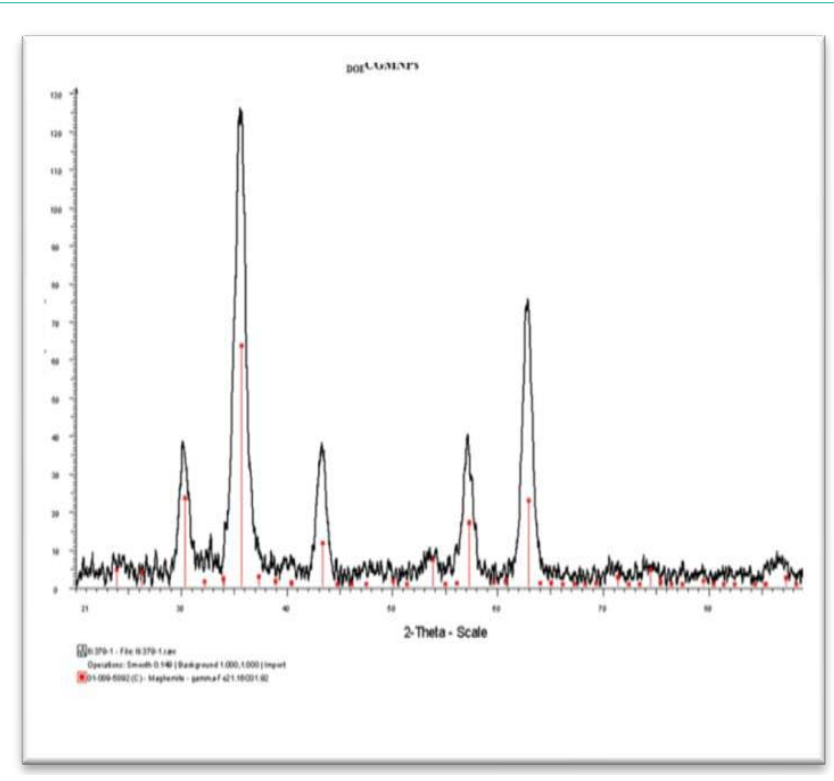

Figure 4: XRD spectrum of ultra-small $6.61 \pm 2.04 \mathrm{~nm}$-sized core $\mathrm{CAN}_{\mathrm{DOE}}{ }^{-\gamma}$ $\mathrm{Fe}_{2} \mathrm{O}_{3} \mathrm{NPS}$.

At this stage of core NPs developmental studies, these optimized $\mathrm{CAN}_{\mathrm{DOE}}-\gamma-\mathrm{Fe}_{2} \mathrm{O}_{3} \mathrm{NPs}$ have been further characterized by various combined analytical, spectroscopic, and microscopy methods. For example, Transmission Electron Microscopy (TEM) (Figure 3) microphotograph indicated the formation of well-shaped spherical crystalline (lattice fringes observation) and non-aggregated NPs. NP crystallinity was further confirmed by both TEM/Selected-Area Electron Diffraction (SAED) pattern and powder X-Ray Diffraction (XRD) analyses (Figure 3, bottom-left \& Figure 4). Both analyses clearly emphasized the four most significant individual $(220,2 \theta$ : $\left.30.266^{\circ}\right),\left(311,2 \theta: 35.651^{\circ}\right),\left(400,2 \theta: 35.651^{\circ}\right), \&\left(440,2 \theta: 62.949^{\circ}\right)$ diffraction planes that characterized a typical spinel crystalline maghemite/magnetite phase (JCPDS card n 39-1346).

\section{GdC-MRI of the inner ear after targeted delivery to the tympanic medial wall}

In the rat studies, MRI measurements were performed using a 4.7-T MRI scanner with a bore diameter of $155 \mathrm{~mm}$ (Pharma Scan; Bruker Bio-Spin, Ettlingen, Germany) and a dedicated rat head coil (linear bird cage coil) with a diameter of $38 \mathrm{~mm}$. The maximum gradient strength was $300 \mathrm{mT} / \mathrm{m}$ with an $80-\mu$ s rise time. The body temperatures of the rats were maintained by circulating warm water, and their respiration patterns were recorded using the Physio Tool-1.0.b.2 program (BrukerBioSpin). The rats were placed in the magnet with their ears positioned at the isocenter. After setting up the geometry of $\mathrm{T}_{2}$-weighted 2-Dimensional (2D) images acquired using Rapid Acquisition with Relaxation Enhancement (RARE) sequences (TR/TE eff 2,500/40 ms, RARE factor 8, matrix size 256 $\times 256$, slice thickness $0.8 \mathrm{~mm}$, FOV $5.0 \times 5.0 \mathrm{~cm}^{2}$, resolution 0.195 $\left.\times 0.195 \mathrm{~mm}^{2}, \mathrm{NEX} 3\right), \mathrm{T}_{1}$-weighted 3D images were acquired with a RARE sequence (TR/TE eff 500/12 ms, RARE factor 16, matrix size $64 \times 64 \times 64$, FOV $0.89 \times 0.89 \times 0.89 \mathrm{~cm}^{3}$, resolution $0.139 \times 0.139$ $\times 0.139 \mathrm{~mm}^{3}$, NEX 2). As a result, Gd-DOTA entered the inner ear efficiently and highlighted the perilymphatic spaces, modiolus, and lateral wall (spiral ligament) (Figure 5). 


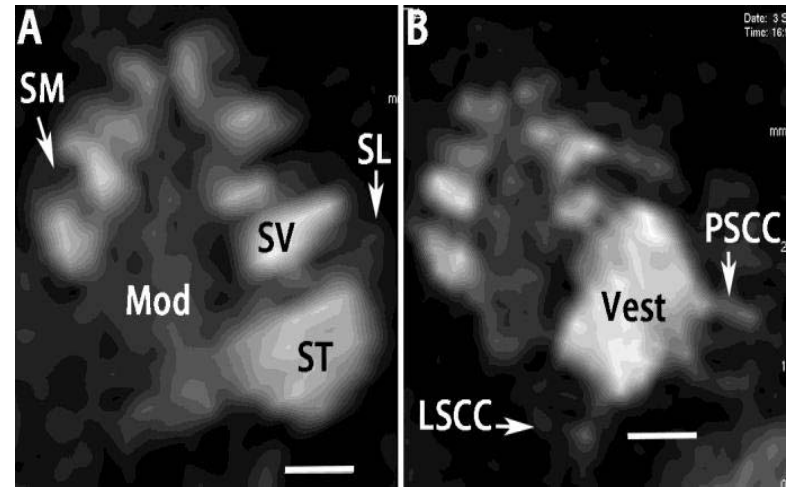

Figure 5: Uptake of Gd-DOTA in rat inner ear $3 \mathrm{~h}$ after targeted delivery to the tympanic medial wall shown by $T_{1}$-wieghted $3 D$ RARE MRI using a 4.7 $\mathrm{T}$ machine. The cochlea was demonstrated in $\mathrm{A}$, and vestibule was shown in B. Mod: Modiolus; LSCC: Lateral Semicircular Canal; PSCC: Posterior Semicircular Canal; SL: Spiral Ligament; SM: Scala Media; ST: Scala Tympani; SV: Scalavestibuli; Vest: Vestibulum. Scale bar=500 $\mu \mathrm{m}$.

MEMRI of the inner ear after targeted delivery to the tympanic medial wall

$\mathrm{T}_{1}$-weighted $3 \mathrm{D}$ images were acquired with a $4.7 \mathrm{~T}$ machine using the same sequences as that used for GdC MRI at various time points. The uptake pattern of $\mathrm{Mn}^{++}$in the inner ear differed from that of Gd-DOTA showing a surface-bound distribution instead of fluiddominant filling. The basilar membrane was obviously enhanced and became more highlighted than the perilymph at $3 \mathrm{~h}$ after delivery (Figure 6).

$\mathrm{CAN}_{\mathrm{DOE}}-\mathrm{Y}-\mathrm{Fe}_{2} \mathrm{O}_{3} \mathrm{NPs}$ of the inner ear after targeted delivery to the tympanic medial wall

T2-weighted 2D images were acquired using a $4.7 \mathrm{~T}$ machine with RARE 2D sequences (TR/ TEeff: 2500/40 ms; RARE factor: 8; matrix

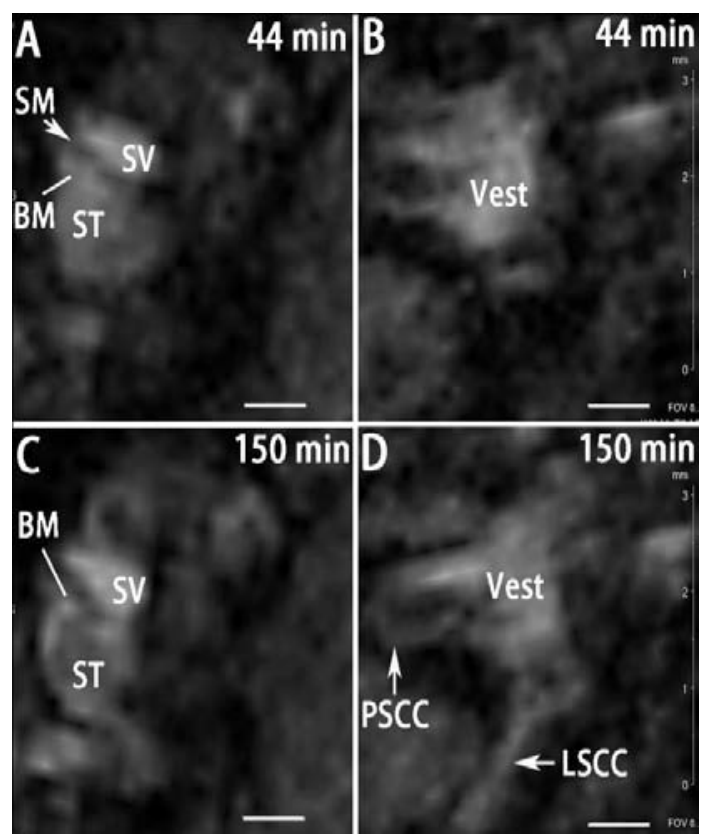

Figure 6: Uptake of $\mathrm{Mn}^{++}$in rat inner ear at different time points after targeted delivery to the tympanic medial wall shown by $T_{1}$-wieghted 3D RARE MRI using a $4.7 \mathrm{~T}$ machine. Scale bar $=500 \mu \mathrm{m}$.
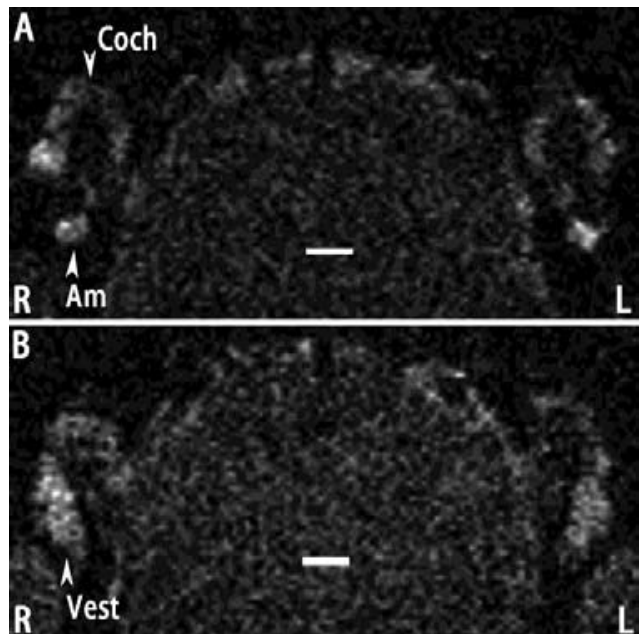

Figure 7: Uptake of SPIONs in the inner ear after targeted delivery to the tympanic medial wall shown by T2-weighted 2D RARE MRI using a $4.7 \mathrm{~T}$ machine. The SPIONs were delivered to the Left side (L). The uptake in the Cochlea (Coch) was shown in A and in the Vestibule (Vest) was shown in B. Am: Ampulla. Scale bar $=1.0 \mathrm{~mm}$.

size: $256 \times 256$; slice thickness: $0.5 \mathrm{~mm}$; FOV: $2.5 \mathrm{~cm}$; resolution: 0.156 $\times 0.156 \mathrm{~mm} 2$; NEX: 5) that was reported previously [16]. The inner ear appeared with a bright signal attributed to the fluids of perilymph and endolymph. Distribution of SPIONs in the inner ear significantly reduced the signal intensity (Figure 7). Quantification using ImageJ $1.48 \mathrm{v}$ (NIH, Maryland, USA) showed that the signal intensities in the cochlea and vestibule of the administration side (left) were lower than that on the contra lateral side (right).

\section{Future Expectations}

A device for the targeted delivery of contrast agents to the tympanic medial wall safely will be developed and launched in the market to facilitate the clinical application of the novel technique. Intratympanic administration of $\mathrm{GdC}$ will be approved for human use in visualization of perilymphatic spaces and the sequential transport of $\mathrm{GdC}$ from perilymph to cerebrospinal fluids around vestibular and cochlear nerves to demonstrate patency problems of the channels and cochlear aqueduct. The biological safety of ${ }_{\mathrm{DOE}}$ CGMNPs will be evaluated and targetable peptides will be conjugated to the ${ }_{D O E}$ CGMNPs for accurate diagnosis of the inner ear diseases. Targeted delivery ${ }_{\text {DOE }}$ CGMNPs will be confirmed with TEM. MEMRI will be developed to demonstrate calcium metabolism in human inner ear.

\section{Acknowledgement}

The work was supported by the EC FP7 collaborative project NANOCI (grant agreement number: 281056) and the National Natural Science Foundation of China (grant number: 81170914/ H1304).

\section{References}

1. Counter SA, Bjelke B, Klason T, Chen Z, Borg E. Magnetic resonance imaging of the cochlea, spiral ganglia and eighth nerve of the guinea pig. Neuroreport. 1999; 10: 473-479.

2. Zou J, Pyykko I, Bjelke B, Bretlau P, Tayamaga T. Endolympahtic hydrops is caused by increased porosity of stria vascularis? Barany Society Meeting; Uppsala, Sweden. 2000. 
3. Zou J, Pyykkö I, Bretlau P, Klason T, Bjelke B . In vivo visualization of endolymphatic hydrops in guinea pigs: magnetic resonance imaging evaluation at 4.7 tesla. Ann Otol Rhinol Laryngol. 2003; 112: 1059-1065.

4. Tervahartiala P, Kivisaari L, Kivisaari R, Virtanen I, StandertskjöldNordenstam CG. Contrast media-induced renal tubular vacuolization. A light and electron microscopic study on rat kidneys. Invest Radiol. 1991; 26: 882 887.

5. Thomsen HS. Gadolinium-based contrast media may be nephrotoxic even at approved doses. Eur Radiol. 2004; 14: 1654-1656.

6. Thakral C, Alhariri J, Abraham JL. Long-term retention of gadolinium in tissues from nephrogenic systemic fibrosis patient after multiple gadoliniumenhanced MRI scans: case report and implications. Contrast Media Mol Imaging. 2007; 2: 199-205.

7. Duan M, Bjelke B, Fridberger A, Counter SA, Klason T, Skjönsberg A, et al. Imaging of the guinea pig cochlea following round window gadolinium application. Neuroreport. 2004; 15: 1927-1930.

8. Zou J, Pyykkö I, Bjelke B, Dastidar P, Toppila E. Communication between the perilymphatic scalae and spiral ligament visualized by in vivo MRI. Audiol Neurootol. 2005; 10: 145-152.

9. Nakashima T, Naganawa S, Sugiura M, Teranishi M, Sone M, Hayashi H, et al. Visualization of endolymphatic hydrops in patients with Meniere's disease. Laryngoscope. 2007; 117: 415-420.

10. Zou J, Yoshida T, Ramadan UA, Pyykkö I. Dynamic enhancement of the rat inner ear after ultra-small-volume administration of Gd-DOTA to the medial wall of the middle ear cavity. ORL J Otorhinolaryngol Relat Spec. 2011; 73 275-281.

11. Pautler RG, Silva AC, Koretsky AP. In vivo neuronal tract tracing using manganese-enhanced magnetic resonance imaging. Magn Reson Med. 1998; 40: 740-748.

12. Lee JW, Park JA, Lee JJ, Bae SJ, Lee SH, Jung JC, et al. Manganeseenhanced auditory tract-tracing MRI with cochlear injection. Magn Reson Imaging. 2007; 25: 652-656.

13. Watanabe T, Frahm J, Michaelis T. Manganese-enhanced MRI of the mouse auditory pathway. Magn Reson Med. 2008; 60: 210-212.

14. Jin SU, Lee JJ, Hong KS, Han M, Park JW, Lee HJ, et al. Intratympanic manganese administration revealed sound intensity and frequency dependent functional activity in rat auditory pathway. Magn Reson Imaging 2013; 31: 1143-1149.
15. Andrews M, Giger ML, Roman BB. Manganese-enhanced MRI detection of impaired calcium regulation in a mouse model of cardiac hypertrophy. NMR Biomed. 2015; 28: 255-263.

16. Zou J, Zhang W, Poe D, Qin J, Fornara A, Zhang Y, et al. MRI manifestation of novel superparamagnetic iron oxide nanoparticles in the rat inner ear. Nanomedicine (Lond). 2010; 5: 739-754.

17. Kang HW, Josephson L, Petrovsky A, Weissleder R, Bogdanov A. Magnetic resonance imaging of inducible $\mathrm{E}$-selectin expression in human endothelial cell culture. Bioconjug Chem. 2002; 13: 122-127.

18. Yang L, Mao H, Wang YA, Cao Z, Peng X, Wang $X$, et al. Single chain epidermal growth factor receptor antibody conjugated nanoparticles for in vivo tumor targeting and imaging. Small. 2009; 5: 235-243.

19. Yang L, Mao H, Cao Z, Wang YA, Peng X, Wang X, et al. Molecular imaging of pancreatic cancer in an animal model using targeted multifunctional nanoparticles. Gastroenterology. 2009; 136: 1514-1525.

20. Israel LL, Lellouche E, Kenett R, Green O, Michaeli S, JP L. Ce3/4+ CationFunctionalized Maghemite Nanoparticles Towards siRNA-Mediated Gene Silencing. . Journal of Materials Chemistry B. 2014; 2: 6215-6225.

21. Zou J. The efficient oval window passage of gadolinium chalete. 4th Annual Meeting of Nano Ear. Chania, Greece. 2010.

22. Zou J, Poe D, Ramadan UA, Pyykkö I. Oval window transport of Gd-dOTA from rat middle ear to vestibulum and scala vestibuli visualized by in vivo magnetic resonance imaging. Ann Otol Rhinol Laryngol. 2012; 121: 119-128.

23. Schachern PA, Paparella MM, Duvall AJ. The normal chinchilla round window membrane. Arch Otolaryngol. 1982; 108: 550-554.

24. Kawabata I, Paparella MM. Fine structure of the round window membrane Ann Otol Rhinol Laryngol. 1971; 80: 13-26.

25. Ohashi M, Ide S, Sawaguchi A, Suganuma T, Kimitsuki T, Komune S. Histochemical localization of the extracellular matrix components in the annular ligament of rat stapediovestibular joint with special reference to fibrillin, 36-kDa microfibril-associated glycoprotein (MAGP-36), and hyaluronic acid. Med Mol Morphol. 2008; 41: 28-33.

26. Tanaka K, Motomura S. Permeability of the labyrinthine windows in guinea pigs. Arch Otorhinolaryngol. 1981; 233: 67-73.
Austin J Radiol - Volume 2 Issue 6 - 2015

ISSN : 2473-0637 | www.austinpublishinggroup.com

Zou et al. (C) All rights are reserved
Citation: Zou J, Ostrovsky S, Israel LL, Lellouche JP and Pyykkö I. Targeted Delivery of Contrast Agents to the Tympanic Medial Wall at Minimum Amount and the Efficient Uptake in the Inner Ear through Oval and Round Windows. Austin J Radiol. 2015; 2(6): 1034. 